\title{
SUATU KAJIAN TENTANG HIMPUNAN FUZZY INTUISIONISTIK
}

\author{
NILA SEFRIANA PUTRI \\ Program Studi Matematika, \\ Fakultas Matematika dan Ilmu Pengetahuan Alam, Universitas Andalas, \\ Kampus UNAND Limau Manis Padang, Indonesia. \\ email : nila.sefriana@gmail.com
}

\begin{abstract}
Abstrak. Pada himpunan fuzzy intuisionistik yang untuk selanjutnya akan disebut dengan IFS, dapat didefinisikan beberapa operasi dasar seperti gabungan, irisan, penjumlahan, perkalian dan komplemen. Selain mendefinisikan operasi dasar, dapat pula didefinisikan beberapa operator serta normalisasi pada IFS. Pada paper ini Penulis mengkaji sifat-sifat aljabar yang terdapat pada IFS dengan menggunakan beberapa operasi dasar, operator dan normalisasi yang telah didefinisikan.
\end{abstract}

Kata Kunci: Himpunan fuzzy intuisionistik, operator, normalisasi, derajat keanggotaan, derajat nonkeanggotaan

\section{Pendahuluan}

Teori himpunan fuzzy pertama kali diperkenalkan oleh Lotfi A. Zadeh [5] pada 1965. Sebelum teori tentang himpunan fuzzy muncul, dikenal sebuah himpunan klasik seringkali disebut dengan himpunan tegas (crisp set) yang keanggotaannya memiliki nilai salah atau benar secara tegas.

Lotfi A. Zadeh [5] mengamati bahwa teori himpunan tegas tidak cukup untuk mengatasi proses perubahan yang halus. Sebagai contoh pertanyaan, "Apakah suhu $50^{\circ}$ termasuk panas? " sulit dijawab dengan tepat jika dengan menggunakan himpunan tegas. Untuk menjawab pertanyan seperti ini logika fuzzy menyediakan apa yang disebut dengan kebenaran fuzzy. Kebenaran fuzzy adalah suatu cara untuk menyatakan derajat A atau bukan A dalam suatu semesta pembicaraan. Biasanya derajat ini dinyatakan dalam persen. Misalnya jawaban dari pertanyaan di atas adalah suhu $50^{\circ}$ termasuk kategori panas 0,6 dan kategori dingin 0,4.

Dewasa ini, telah banyak peneliti yang terus mengembangkan dan mengaplikasikan teori ini pada kehidupan nyata, seperti Krassimir Anatassov [1] pada tahun 1986 memperkenalkan himpunan fuzzy intuisionistik yang merupakan perumuman dari konsep himpunan fuzzy. Pada tahun 2014, P.A. Ejegwa dkk. [2] meninjau kembali tentang himpunan fuzzy intuisionistik. Karena pada teori himpunan fuzzy intuisionistik [1], pada kenyataannya, tidak selalu benar bahwa derajat ketidakanggotaan dari setiap elemen himpunan fuzzy sama dengan satu dikurang derajat keanggotaan, karena ada suatu derajat yang tak pasti.

Dalam tulisan ini akan dikaji kembali tentang sifat-sifat dari himpunan fuzzy intuisionistik (intuitionistic fuzzy set) yang ditulis P.A. Ejegwa dkk [2]. 


\section{Himpunan Fuzzy Intuisionistik}

Definisi 2.1. [5] Misalkan X suatu himpunan yang tak kosong. Himpunan fuzzy $A$ atas $X$ didefinisikan sebagai:

$$
A=\left\{\left\langle x, \mu_{A}(x)\right\rangle: x \in X\right\},
$$

dimana $\mu_{A}: X \longrightarrow[0,1]$, dan $\mu_{A}(x)$ disebut derajat keanggotaan dari $x$ pada himpunan fuzzy $A$.

Selanjutnya akan diperkenalkan teori-teori tentang himpunan fuzzy intuisionistik (IFS).

Definisi 2.2. [2] Misalkan $X$ adalah himpunan semesta yang tak kosong. Himpunan fuzzy intuisionistik (IFS) $A$ atas $X$ adalah:

$$
A=\left\{\left\langle x, \mu_{A}(x), v_{A}(x)\right\rangle ; x \in X\right\}
$$

dimana $\mu_{A}, v_{A}: X \longrightarrow[0,1]$ berturut-turut menyatakan derajat keanggotaan dan derajat non-keanggotaan dari $x \in X$ pada himpunan $A$, dan selanjutnya, untuk setiap $x \in X$ berlaku:

$$
\begin{aligned}
0 & \leq \mu_{A}(x)+v_{A}(x) \leq 1, \text { dan } \\
\pi_{A}(x) & =1-\mu_{A}(x)-v_{A}(x),
\end{aligned}
$$

merupakan derajat kabur keanggotaan dari $x \in X$ pada IFS $A$, artinya $\pi_{A}(x)$ menyatakan ketidaktahuan apakah $x$ mempunyai derajat keanggotaan atau tidak pada IFS $A$, dengan $\pi_{A}: X \longrightarrow[0,1]$ untuk setiap $x \in X$.

Definisi 2.3. [2] Misalkan $A \in X$ adalah suatu himpunan fuzzy intuisionistik, maka

(1) $\pi_{A}(x)=1-\mu_{A}(x)-v_{A}(x)$, disebut derajat ketaktahuan dari $x$ pada IFS A.

(2) $\partial_{A}(x)=\mu_{A}(x)+\pi_{A}(x)$, dimana $\mu_{A}(x)$ disebut derajat pendukung dari $x$ pada IFS $A$.

(3) $\eta_{A}(x)=v_{A}(x)+\pi_{A}(x)$, dimana $v_{A}(x)$ disebut derajat penolak dari $x$ pada IFS A.

Definisi 2.4. [2] (IFS Serupa) Dua IFS A dan B atas himpunan semesta tak kosong $X$ dikatakan mirip atau serupa, jika terdapat $\mu_{A}(x)=\mu_{B}(x)$ atau $v_{A}(x)=$ $v_{B}(x)$ untuk setiap $x \in X$.

Definisi 2.5. [2] (IFS Sebanding) Dua IFS $A$ dan $B$ atas himpunan semesta tak kosong $X$ dikatakan sama atau sebanding, dinotasikan $A=B$, jika $\mu_{A}(x)=\mu_{B}(x)$ dan $v_{A}(x)=v_{B}(x)$ untuk setiap $x \in X$.

Definisi 2.6. [2] (IFS Ekuivalen) Dua IFS A dan B atas himpunan semesta yang tak kosong $X$ dikatakan saling ekuivalen, $A$ ekuivalen $B$, dinotasikan $A \sim B$, jika ada fungsi bijektif (satu-satu dan pada), dimana, $f: \mu_{A} \longrightarrow \mu_{B}$ dan $f: v_{A} \longrightarrow v_{B}$. Fungsi $f$ didefinisikan sebagai korespondensi satu-satu dan pada antara $A$ dan $B$. 
Definisi 2.7. [2] (IFS Inklusif) Misalkan $A$ dan $B$ IFS atas $X, A$ dikatakan subset dari $B$ (atau $B$ superset dari $A$ ), dinotasikan $A \subseteq B$, jika $\mu_{A}(x) \leq \mu_{B}(x)$ dan $v_{A}(x) \geq v_{B}(x)$; untuk setiap $x \in X$.

Definisi 2.8. [2] (Proper Subset) Himpunan $A$ adalah proper subset dari B, dinotasikan $A \subset B$, jika $A \subseteq B$ dan $A \neq B$. Artinya untuk setiap $x \in X$ berlaku: $\mu_{A}(x)<\mu_{B}(x)$ dan $v_{A}(x)>v_{B}(x)$.

Definisi 2.9. [2] (Dominasi) IFS A didominasi oleh IFS B yang lain, dinotasikan $A \preceq B$, jika ada fungsi satu-satu dari $A$ ke $B$.

Definisi 2.10. [2] (Relasi) Misalkan A, B dan $C$ adalah IFS atas $X$.

(1) Jika $A \preceq A$, maka $\preceq$ disebut relasi refleksif.

(2) $A \preceq B$ dan $B \preceq A$, maka $\preceq$ disebut relasi simetris.

(3) $A \preceq B$ dan $B \preceq C \Longrightarrow A \preceq C$, maka disebut relasi transitif.

Akibat 2.11. [2] Untuk setiap IFS $A$ dan $B$ atas $X$, jika $A \preceq B$ dan $B \preceq A$, maka $A \sim B$.

Akibat 2.12. [2] Untuk setiap IFS $A$ dan $B$ atas $X$, jika $A \preceq A, A \preceq B$ dan $B \preceq A$ maka $A$ dan $B$ sebanding satu sama lain.

Bukti. Misalkan $A$ dan $B$ IFS atas $X, A \preceq A, A \preceq B$ dan $B \preceq A$. Akan ditunjukkan bahwa $A$ dan $B$ sebanding satu sama lain.

Karena $A \preceq A$, maka berdasarkan Definisi 2.9, terdapat fungsi $f$ satu-satu dari $A$ ke $A$ dengan $f: \mu_{A} \longrightarrow \mu_{A}$ dan $f: v_{A} \longrightarrow v_{A}$.

Karena $B \preceq A$, maka berdasarkan Definisi 2.9 ada fungsi $f$ satu-satu dari $B$ ke $A$ dengan $f: \mu_{B} \longrightarrow \mu_{A}$ dan $f: v_{B} \longrightarrow v_{A}$. Perhatikan bahwa:

(i) Karena $f: \mu_{A} \longrightarrow \mu_{A}$ dan $f: \mu_{B} \longrightarrow \mu_{A}$, maka $f\left(\mu_{A}(x)\right)=f\left(\mu_{B}(x)\right)$ untuk $x \in X$. Karena $f$ satu-satu maka $\mu_{A}(x)=\mu_{B}(x)$ untuk setiap $x \in X$.

(ii) Karena $f: v_{A} \longrightarrow v_{A}$ dan $f: v_{B} \longrightarrow v_{A}$ maka $f\left(v_{A}(x)\right)=f\left(v_{B}(x)\right)$ untuk $x \in X$. Karena $f$ satu-satu maka $v_{A}(x)=v_{B}(x)$ untuk setiap $x \in X$.

Dari (i) dan (ii) diperoleh untuk setiap $x \in X$ berlaku $\mu_{A}(x)=\mu_{B}(x)$ dan $v_{A}(x)=$ $v_{B}(x)$, yang berarti bahwa $A$ dan $B$ sebanding satu sama lain.

Teorema 2.13. [7] (Maksimum dan Minimum) Untuk setiap $a, b, c \in \mathbb{R}$ berlaku,

(a) $\max (a, \min (b, c))=\min (\max (a, b), \max (a, c))$.

(b) $\min (a, \max (b, c))=\max (\min (a, b), \min (a, c))$.

Definisi 2.14. [7] (Supremum dan Infimum) Misalkan $S$ adalah suatu himpunan bagian yang tak kosong di $\mathbb{R}$.

(a) Jika $S$ terbatas di atas, maka $u \in \mathbb{R}$ dikatakan supremum (atau batas atas terkecil) dari $S$ jika memenuhi kondisi berikut:

(1) u adalah batas atas dari $S$, dan 
(2) jika $v \in \mathbb{R}$ adalah sebarang batas atas dari $S$, maka $u \leq v$.

(b) Jika $S$ terbatas di bawah, maka $w \in \mathbb{R}$ dikatakan infimum (atau batas bawah terbesar) dari $S$ jika memenuhi kondisi berikut:

(1) $w$ adalah batas bawah dari $S$, dan

(2) jika $t \in \mathbb{R}$ adalah sebarang batas bawah dari $S$, maka $w \geq t$.

\section{Suatu Kajian tentang Himpunan Fuzzy Intuisionistik}

Pada bagian ini, akan diperkenalkan teori-teori mengenai himpunan fuzzy intuisionistik yang meliputi operasi-operasi dasar, operator-operator modal dan normalisasi pada himpunan fuzzy intuisionistik.

\subsection{Operasi Dasar Pada IFS}

Dari [2], untuk setiap IFS A dan B atas X, berlaku:

(1) Himpunan Bagian $A \subseteq B \Longleftrightarrow \mu_{A}(x) \leq \mu_{B}(x)$ dan $v_{A}(x) \geq v_{B}(x)$ untuk setiap $x \in X$.

(2) Komplemen $A^{c}=\left\{\left\langle x, v_{A}(x), \mu_{A}(x)\right\rangle ; x \in X\right\}$.

(3) Gabungan $A \cup B=\left\{\left\langle x, \max \left(\mu_{A}(x), \mu_{B}(x)\right), \min \left(v_{A}(x), v_{B}(x)\right)\right\rangle ; x \in X\right\}$.

(4) Irisan $A \cap B=\left\{\left\langle x, \min \left(\mu_{A}(x), \mu_{B}(x)\right), \max \left(v_{A}(x), v_{B}(x)\right)\right\rangle ; x \in X\right\}$.

(5) Penjumlahan $A \bigoplus B=\left\{\left\langle x, \mu_{A}(x)+\mu_{B}(x)-\mu_{A}(x) \cdot \mu_{B}(x), v_{A}(x) \cdot v_{B}(x)\right\rangle ; x \in X\right\}$.

(6) Perkalian $A \otimes B=\left\{\left\langle x, \mu_{A}(x) \cdot \mu_{B}(x), v_{A}(x)+v_{B}(x)-v_{A}(x) \cdot v_{B}(x)\right\rangle ; x \in X\right\}$.

\subsection{Sifat-sifat Aljabar Pada IFS}

Misalkan $A, B$ dan $C$ adalah IFS atas $X$, dengan $A=\left\{\left\langle x, \mu_{A}(x), v_{A}(x)\right\rangle ; x \in\right.$ $X\}, B=\left\{\left\langle x, \mu_{B}(x), v_{B}(x)\right\rangle ; x \in X\right\}$ dan $C=\left\{\left\langle x, \mu_{C}(x), v_{C}(x)\right\rangle ; x \in X\right\}$, maka berlaku

(1) Hukum Komplemen

$$
\left(A^{c}\right)^{c}=A \text {. }
$$

(2) Hukum Idempoten

(i) $A \cup A=A$.

(ii) $A \cap A=A$.

(3) Hukum Komutatif

(i) $A \cup B=B \cup A$.

(ii) $A \cap B=B \cap A$.

(4) Hukum Assosiatif

(i) $(A \cup B) \cup C=A \cup(B \cup C)$. 
(ii) $(A \cap B) \cap C=A \cap(B \cap C)$.

(5) Hukum Distributif

(i) $A \cup(B \cap C)=(A \cup B) \cap(A \cup C)$.

(ii) $A \cap(B \cup C)=(A \cap B) \cup(A \cap C)$.

(6) Hukum de Morgan

(i) $(A \cup B)^{c}=A^{c} \cap B^{c}$.

(ii) $(A \cap B)^{c}=A^{c} \cup B^{c}$.

(7) Hukum Absorpsi

(i) $A \cap(A \cup B)=A$.

(ii) $A \cup(A \cap B)=A$.

(8) Komutatif terhadap penjumlahan dan perkalian IFS

(i) $A \oplus B=B \oplus A$.

(ii) $A \otimes B=B \otimes A$.

(9) Asosiatif Penjumlahan dan Perkalian IFS

(i) $A \oplus(B \oplus C)=(A \oplus B) \oplus C$.

(ii) $A \otimes(B \otimes C)=(A \otimes B) \otimes C$.

(10) Perkalian dan Penjumlahan Komplemen IFS

(i) $(A \oplus B)^{c}=A^{c} \otimes B^{c}$.

(ii) $(A \otimes B)^{c}=A^{c} \bigoplus B^{c}$.

(11) Distributif Perkalian dan Penjumlahan IFS

(i) $A \oplus(B \cup C)=(A \oplus B) \cup(A \oplus C)$.

(ii) $A \oplus(B \cap C)=(A \oplus B) \cap(A \oplus C)$.

(iii) $A \otimes(B \cup C)=(A \otimes B) \cup(A \otimes C)$.

(iv) $A \otimes(B \cap C)=(A \otimes B) \cap(A \otimes C)$.

\subsection{Beberapa Operator Pada IFS}

Berikut akan dijelaskan dua operator yang mentransformasikan setiap IFS ke himpunan fuzzy.

Definisi 3.1. [2] (Operator) Misalkan $X$ adalah himpunan semesta yang tak kosong. Jika A adalah IFS atas X, didefinisikan dua operator sebagai berikut:

(i) $\square A=\left\{\left\langle x, \mu_{A}(x)\right\rangle ; x \in X\right\}=\left\{\left\langle x, \mu_{A}(x), 1-\mu_{A}(x)\right\rangle ; x \in X\right\}$.

(ii) $\diamond A=\left\{\left\langle x, 1-v_{A}(x)\right\rangle ; x \in X\right\}=\left\{\left\langle x, 1-v_{A}(x), v_{A}(x)\right\rangle ; x \in X\right\}$.

Teorema 3.2. [2] Misalkan X adalah himpunan semesta yang tak kosong. Untuk setiap IFS A atas $X$ berlaku:
(a) $\square \square A=\square A$.
(b) $\square \diamond A=\diamond A$.
(c) $\diamond \square A=\square A$.
(d) $\diamond \diamond A=\diamond A$. 
Bukti. Akan ditunjukkan bahwa (a) berlaku. Pembuktian untuk (b) - (d) dilakukan dengan cara yang sama.

Misalkan X adalah himpunan semesta yang tak kosong dan misalkan A adalah IFS atas X. Akan ditunjukkan bahwa $\square \square A=\square A$. Karena himpunan A adalah IFS atas $\mathrm{X}$, maka $A=\left\{\left\langle x, \mu_{A}(x), v_{A}(x)\right\rangle ; x \in X\right\}$. Perhatikan bahwa:

$$
\begin{aligned}
\square \square A & =\square \square\left(\left\{\left\langle x, \mu_{A}(x), v_{A}(x)\right\rangle ; x \in X\right\}\right) \\
& =\square\left(\left\{\left\langle x, \mu_{A}(x)\right\rangle ; x \in X\right\}\right)=\square\left(\left\{\left\langle x, \mu_{A}(x), 1-\mu_{A}(x)\right\rangle ; x \in X\right\}\right) \\
& =\left\{\left\langle x, \mu_{A}(x)\right\rangle ; x \in X\right\}=\left\{\left\langle x, \mu_{A}(x), 1-\mu_{A}(x)\right\rangle ; x \in X\right\} \\
& =\square A .
\end{aligned}
$$

Karena himpunan A IFS atas X diambil sebarang, maka dapat disimpulkan bahwa untuk setiap IFS A atas X berlaku $\square \square A=\square A$.

Teorema 3.3. [2] Misalkan X adalah himpunan semesta tak kosong. Untuk setiap dua IFS $A$ dan $B$ atas $X$ berlaku:

(a) $\square(A \cap B)=\square A \cap \square B$

(b) $\diamond(A \cap B)=\diamond A \cap \diamond B$.

(c) $\square(A \cup B)=\square A \cup \square B$.

(d) $\diamond(A \cup B)=\diamond A \cup \diamond B$.

(e) $\square(A \bigoplus B)=\square A \bigoplus \square B$.

(f) $\square(A \otimes B)=\square A \otimes \square B$.

(g) $\diamond(A \oplus B)=\diamond A \bigoplus \diamond B$.

(h) $\diamond(A \otimes B)=\diamond A \otimes \diamond B$.

Bukti. Misalkan $X$ adalah himpunan semesta tak kosong. Ambil dua IFS A dan $\mathrm{B}$ atas X. Akan ditunjukkan bahwa (a) berlaku. Pembuktian (b) - (h) dilakukan dengan cara yang sama.

Akan ditunjukkan bahwa $\square(A \cap B)=\square A \cap \square B$. Karena $A, B$ IFS atas X, maka $A=\left\{\left\langle x, \mu_{A}(x), v_{A}(x)\right\rangle ; x \in X\right\}$ dan $B=\left\{\left\langle x, \mu_{B}(x), v_{B}(x)\right\rangle ; x \in X\right\}$. Perhatikan bahwa:

$$
\begin{aligned}
\square(A \cap B) & =\square\left(\left\{\left\langle x, \mu_{A}(x), v_{A}(x)\right\rangle ; x \in X\right\} \cap\left\{\left\langle x, \mu_{B}(x), v_{B}(x)\right\rangle ; x \in X\right\}\right) \\
& =\square\left(\left\{\left\langle x, \min \left(\mu_{A}(x), \mu_{B}(x)\right), \max \left(v_{A}(x), v_{B}(x)\right)\right\rangle ; x \in X\right\}\right) \\
& \left.=\left\{\left\langle x, \min \left(\mu_{A}(x), \mu_{B}(x)\right), 1-\min \left(\mu_{A}(x), \mu_{B}(x)\right)\right\rangle ; x \in X\right\}\right) \\
& \left.=\left\{\left\langle x, \min \left(\mu_{A}(x), \mu_{B}(x)\right), \max \left(1-\mu_{A}(x), 1-\mu_{B}(x)\right)\right\rangle ; x \in X\right\}\right) \\
& =\left(\left\{\left\langle x, \mu_{A}(x), 1-\mu_{A}(x)\right\rangle ; x \in X\right\}\right) \cap\left(\left\{\left\langle x, \mu_{B}(x), 1-\mu_{B}(x)\right\rangle ; x \in X\right\}\right) \\
& =\square\left(\left\{\left\langle x, \mu_{A}(x), v_{A}(x)\right\rangle ; x \in X\right\}\right) \cap \square\left(\left\{\left\langle x, \mu_{B}(x), v_{B}(x)\right\rangle ; x \in X\right\}\right) \\
& =\square A \cap \square B .
\end{aligned}
$$

Karena $A$, dan $B$ IFS atas $\mathrm{X}$ diambil sebarang, maka dapat disimpulkan bahwa untuk setiap $A$ dan $B$ IFS atas X, berlaku $\square(A \cap B)=\square A \cap \square B$.

Definisi 3.4. [1] Misalkan X adalah himpunan semesta tak kosong. Untuk setiap IFS $A$ dan $B$ atas $X$, didefinisikan relasi $\subset_{\square}$ dan $\subset_{\diamond}$ sebagai berikut: 
(a) $A \subset_{\square} B \Longleftrightarrow \mu_{A}(x) \leq \mu_{B}(x)$ untuk setiap $x \in X$.

(b) $A \subset \diamond B \Longleftrightarrow v_{A}(x) \geq v_{B}(x)$ untuk setiap $x \in X$.

Teorema 3.5. [2] Misalkan X himpunan semesta yang tak kosong, dan misalkan himpunan $A$ dan $B$ merupakan IFS atas $X$, maka berlaku:

(1) $A \subset \square B \Longleftrightarrow \square A \subseteq \square B$.

(2) $A \subset \diamond B \Longleftrightarrow \diamond A \subseteq \diamond B$.

Bukti. Misalkan X himpunan yang tak kosong, dan misalkan A dan B adalah IFS atas X. Akan ditunjukkan pembuktian bagian (1). Bukti bagian (2) dilakukan dengan cara yang sama.

(1) ( $\Longrightarrow$ ) Misalkan $A \subset \square B$. Akan ditunjukkan bahwa $\square A \subseteq \square B$, yaitu dengan menunjukkan:

(i) $\mu_{A}(x) \leq \mu_{B}(x)$ untuk setiap $x \in X$.

(ii) $1-\mu_{A}(x) \geq 1-\mu_{B}(x)$ untuk setiap $x \in X$.

Perhatikan bahwa :

(a) Karena $A \subset \square B$, maka $\mu_{A}(x) \leq \mu_{B}(x)$ untuk setiap $x \in X$.

(b) Karena $\mu_{A}(x) \leq \mu_{B}(x)$, jelas bahwa $1-\mu_{A}(x) \geq 1-\mu_{B}(x)$ untuk setiap $x \in X$.

Karena (a) dan (b) maka diperoleh $\square A \subseteq \square B$.

(1) ( $\Longleftarrow$ ) Misalkan $\square A \subseteq \square B$. Akan ditunjukkan bahwa $A \subset \square B$, yaitu dengan menunjukkan bahwa $\mu_{A}(x) \leq \mu_{B}(x)$ untuk setiap $x \in X$. Perhatikan bahwa:

(a) Karena $\square A \subseteq \square B$ maka $\mu_{A}(x) \leq \mu_{B}(x)$ untuk setiap $x \in X$.

(b) Karena $\mu_{A}(x) \leq \mu_{B}(x)$ untuk setiap $x \in X$ maka $A \subset_{\square} B$.

Karena $A$ dan $B$ IFS sebarang, maka dapat disimpulakan bahwa untuk setiap IFS A dan B berlaku $A \subset_{\square} B \Longleftrightarrow \square A \subseteq \square B$.

\subsection{Normalisasi dari Himpunan Fuzzy Intuisionistik}

Setelah mendefinisikan beberapa operasi-operasi dasar dan operator modal pada IFS, selanjutnya akan dijelaskan normalisasi dari IFS.

Definisi 3.6. [2] Misalkan $X$ adalah himpunan semesta yang tak kosong, normalisasi dari IFS A dinotasikan sebagai NORM $(A)$ didefinisikan sebagai:

$$
\begin{aligned}
\operatorname{NORM}(A) & =\left\{\left\langle x, \mu_{\text {NORM }(A)}(x), v_{\text {NORM }(A)}(x)\right\rangle ; x \in X\right\} \text { dimana } \\
\mu_{\text {NORM }(A)}(x) & =\frac{\mu_{A}(x)}{\sup \left(\mu_{A}\right)}, \\
v_{\text {NORM }(A)}(x) & =\frac{v_{A}(x)-\inf \left(v_{A}\right)}{1-\inf \left(v_{A}\right)}, \text { dengan } \\
\sup \left(\mu_{A}\right) & =\text { supremum }\left\{\mu_{A}(x) ; \forall x \in X\right\}, \text { dan } \\
\inf \left(v_{A}\right) & =\text { infimum }\left\{v_{A}(x) ; \forall x \in X\right\} .
\end{aligned}
$$


Dengan mendefinisikan

$$
\begin{aligned}
\pi_{\operatorname{NORM}(A)}(x) & =1-\mu_{\operatorname{NORM}(A)}(x)-v_{\operatorname{NORM}(A)}(x), \text { maka } \\
\operatorname{NORM}(A) & =\left\{\left\langle x, \mu_{\operatorname{NORM}(A)}(x), v_{\operatorname{NORM}(A)}(x), \pi_{\operatorname{NORM}(A)}(x)\right\rangle ; x \in X\right\} .
\end{aligned}
$$

Proposisi 3.7. [4] Misalkan X adalah himpunan semesta tak kosong. Untuk setiap IFS $A$ atas $X$ berlaku:

(i) $\operatorname{Jika}_{A}(x)=0$, maka $\pi_{N O R M(A)}(x)=0$.

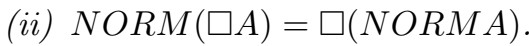

(iii) $\operatorname{NORM}(\diamond A)=\diamond(N O R M A)$.

Menurut [6], Proposisi 3.7 tidak tepat dengan premis itu saja. Proposisi 3.7 berlaku jika ditambahkan asumsi bahwa $\pi_{A}(x)=0$ untuk setiap $x \in X$.

Bukti. Misalkan X adalah himpunan yang tak kosong dan misalkan A adalah IFS atas X. Akan ditunjukkan bagian (i). Untuk bagian (ii) - (iii) pembuktian dilakukan dengan cara yang sama.

Misalkan $\pi_{A}(x)=0$. Akan ditunjukkan bahwa $\pi_{N O R M(A)}(x)=0$. Karena $A$ adalah IFS maka, $\pi_{A}(x)=1-\mu_{A}(x)-v_{A}(x)$. untuk suatu $x \in X$. Karena $\pi_{A}(x)=0$ maka, $0=1-\mu_{A}(x)-v_{A}(x)$, atau $1=\mu_{A}(x)+v_{A}(x)$, atau $\mu_{A}(x)=1-v_{A}(x)$, atau $v_{A}(x)=1-\mu_{A}(x)$. Karena $\pi_{A}(x)=0$ maka, $\sup \left(\mu_{A}\right)+\inf \left(v_{A}\right)=1$ atau $\sup \left(\mu_{A}\right)=1-\inf \left(v_{A}\right)$, atau $\inf \left(v_{A}\right)=1-\sup \left(\mu_{A}\right)$.

Perhatikan bahwa:

$$
\begin{aligned}
\pi_{\text {NORM }(A)}(x) & =1-\mu_{\text {NORM }(A)}(x)-v_{\text {NORM }(A)}(x) \\
& =1-\frac{\mu_{A}(x)}{\sup \left(\mu_{A}\right)}-\left(\frac{v_{A}(x)-\inf \left(v_{A}\right)}{1-\inf \left(v_{A}\right)}\right) \\
& =1-\left(\frac{\mu_{A}(x)}{\sup \left(\mu_{A}\right)}+\left(\frac{v_{A}(x)-\inf \left(v_{A}\right)}{\sup \left(\mu_{A}\right)}\right)\right) \\
& =1-\left(\frac{\mu_{A}(x)+v_{A}(x)-\inf \left(v_{A}\right)}{\sup \left(\mu_{A}\right)}\right) \\
& =1-\left(\frac{1-\inf \left(v_{A}\right)}{\sup \left(\mu_{A}\right)}\right) \\
& =\frac{\sup \left(\mu_{A}\right)}{\sup \left(\mu_{A}\right)}-\left(\frac{1-\inf \left(v_{A}\right)}{\sup \left(\mu_{A}\right)}\right) \\
& =\frac{\sup \left(\mu_{A}\right)-1+\inf \left(v_{A}\right)}{\sup \left(\mu_{A}\right)} \\
& =\frac{\sup \left(\mu_{A}\right)+\inf \left(v_{A}\right)-1}{\sup \left(\mu_{A}\right)} \\
& =\frac{1-1}{\sup \left(\mu_{A}\right)} \\
& =\frac{0}{\sup \left(\mu_{A}\right)} \\
& =0 .
\end{aligned}
$$

Akibat 3.8. Untuk suatu A IFS atas $X$, dengan $\pi_{A}(x)=0$, maka berlaku: 
(i $\operatorname{NORM}(\square A)=\operatorname{NORM}(\diamond A)$.

(ii) $\square \operatorname{NORM}(A)=\diamond N O R M(A)$.

Bukti. Misalkan A IFS atas X, dengan $\pi_{A}(x)=0$. Akan ditunjukkan bagian (i). Untuk bagian (ii) pembuktian dilakukan dengan cara yang sama.

Akan ditunjukkan bahwa $\operatorname{NORM}(\square A)=\operatorname{NORM}(\diamond A)$. Karena $\pi_{A}(x)=0$ maka $v_{A}(x)=1-\mu_{A}(x)$. Perhatikan bahwa:

$$
\begin{aligned}
& \operatorname{NORM}(\square A)=\operatorname{NORM}\left(\left\{\left\langle x, \mu_{A}(x), 1-\mu_{A}(x)\right\rangle ; x \in X\right\}\right) \\
& =\left\{\left\langle x, \frac{\mu_{A}(x)}{\sup \left(\mu_{A}\right)}, \frac{\left(1-\mu_{A}(x)\right)-\inf \left(1-\mu_{A}\right)}{1-\inf \left(1-\mu_{A}\right)}\right\rangle ; x \in X\right\} \\
& =\left\{\left\langle x, \frac{1-v_{A}(x)}{\sup \left(1-v_{A}\right)}, \frac{v_{A}(x)-\inf \left(v_{A}\right)}{1-\inf \left(v_{A}\right)}\right\rangle ; x \in X\right\} \\
& =\left\{\left\langle x, \frac{1-v_{A}(x)}{\sup \left(1-v_{A}\right)}, v_{N O R M(A)}(x)\right\rangle ; x \in X\right\} \\
& =\left\{\left\langle x, \frac{1-v_{A}(x)}{1-\inf \left(v_{A}\right)}, v_{N O R M(A)}(x)\right\rangle ; x \in X\right\} \\
& =\left\{\left\langle x, \frac{1-v_{A}(x)-\inf \left(v_{A}\right)+\inf \left(v_{A}\right)}{1-\inf \left(v_{A}\right)}, v_{N O R M(A)}(x)\right\rangle ; x \in X\right\} \\
& =\left\{\left\langle x, \frac{1-\inf \left(v_{A}\right)}{1-\inf \left(v_{A}\right)}-\frac{v_{A}(x)-\inf \left(v_{A}\right)}{1-\inf \left(v_{A}\right)}, v_{N O R M(A)}(x)\right\rangle ; x \in X\right\} \\
& =\left\{\left\langle x, 1-v_{N O R M(A)}(x), v_{N O R M(A)}(x)\right\rangle ; x \in X\right\} \\
& =\operatorname{NORM}(\diamond A) \text {. }
\end{aligned}
$$

\section{Kesimpulan}

Misalkan $X$ atas himpunan semesta tak kosong, misalkan $A, B$ dan $C$ merupakan IFS atas $X$; maka berlaku:

(1) Sifat-sifat aljabar pada IFS, yaitu
(a) Hukum Komplemen.
(b) Hukum idempoten.
(c) Hukum Komutatif.
(d) Hukum Assosiatif.
(e) Hukum Distributif.
(f) Hukum De Morgan.
(g) Hukum Absorpsi.
(h) Komutatif terhadap penjumlahan dan perkalian IFS.
(i) Assosiatif penjumlahan dan perkalian IFS.
(j) Distributif perkalian dan penjumlahan IFS

(2) Sifat-sifat pada operator $\square A$ dan $\diamond A$ :
(a) $\square \square A=\square A$.
(b) $\square \diamond A=\diamond A$.
(c) $\diamond \square A=\square A$.
(d) $\diamond \diamond A=\diamond A$. 

(e) $\square(A \cap B)=\square A \cap \square B$.
(f) $\diamond(A \cap B)=\diamond A \cap \diamond B$.
(g) $\square(A \cup B)=\square A \cup \square B$.
(h) $\diamond(A \cup B)=\diamond A \cup \diamond B$.
(i) $\square(A \oplus B)=\square A \oplus \square B$.
(j) $\square(A \otimes B)=\square A \otimes \square B$.
(k) $\diamond(A \oplus B)=\diamond A \oplus \diamond B$.
(l) $\diamond(A \otimes B)=\diamond A \otimes \diamond B$.

(3) Sifat-sifat pada normalisasi IFS:
(a) Jika $\pi_{A}(x)=0$, maka $\pi_{N O R M(A)}(x)=0$.
(b) $\operatorname{NORM}(\square A)=\square($ NORMA).
(c) $N O R M(\diamond A)=\diamond(N O R M A)$.
(d) $\operatorname{NORM}(\square A)=\operatorname{NORM}(\diamond A)$.
(e) $\square \operatorname{NORM}(A)=\diamond N O R M(A)$.

\section{Ucapan Terima kasih}

Penulis mengucapkan terima kasih kepada Bapak Admi Nazra, Ibu Nova Noliza Bakar, Bapak Mahdhivan Syafwan, Bapak I Made Arnawa, dan Ibu Lyra Yulianti yang telah memberikan masukan dan saran sehingga paper ini dapat diselesaikan dengan baik.

\section{Daftar Pustaka}

[1] Atanassov, K.T. 1986. Intuitionistic Fuzzy Sets. Fuzzy Sets and Systems. 20: 87 $-96$

[2] Ejegwa, P. A, Akowe, S.O dan Ikyule, J.M. 2014. An Overview On Intuitionistic Fuzzy Sets. International Journal of Scientific and Techonologi Research. 3: 142 -145 .

[3] Ejegwa, P. A, Akowe. 2015. Intuitionistic Fuzzy Sets Theory in Decision Making. Germany: LAP LAMBERT Academic Publishing.

[4] Supriya, K. De, Biswas, R. dan Roy, A.R. 2000. Some operations on intuitionistic fuzzy sets.Fuzzy sets and systems. 114: $477-484$

[5] Zadeh, L.A. 1965. Fuzzy Sets. Information and Control. 8: 338 - 353

[6] Zeng, W dan Li, H. 2006. Note on some operations on intuitionistic fuzzy sets. Fuzzy sets and systems.157: 990 - 999

[7] Bartle, R. G. and Sherbert, D. R. 2000. Introduction to Real Analysis, Third edition. Urbana-Champaign: University of Illinois. 